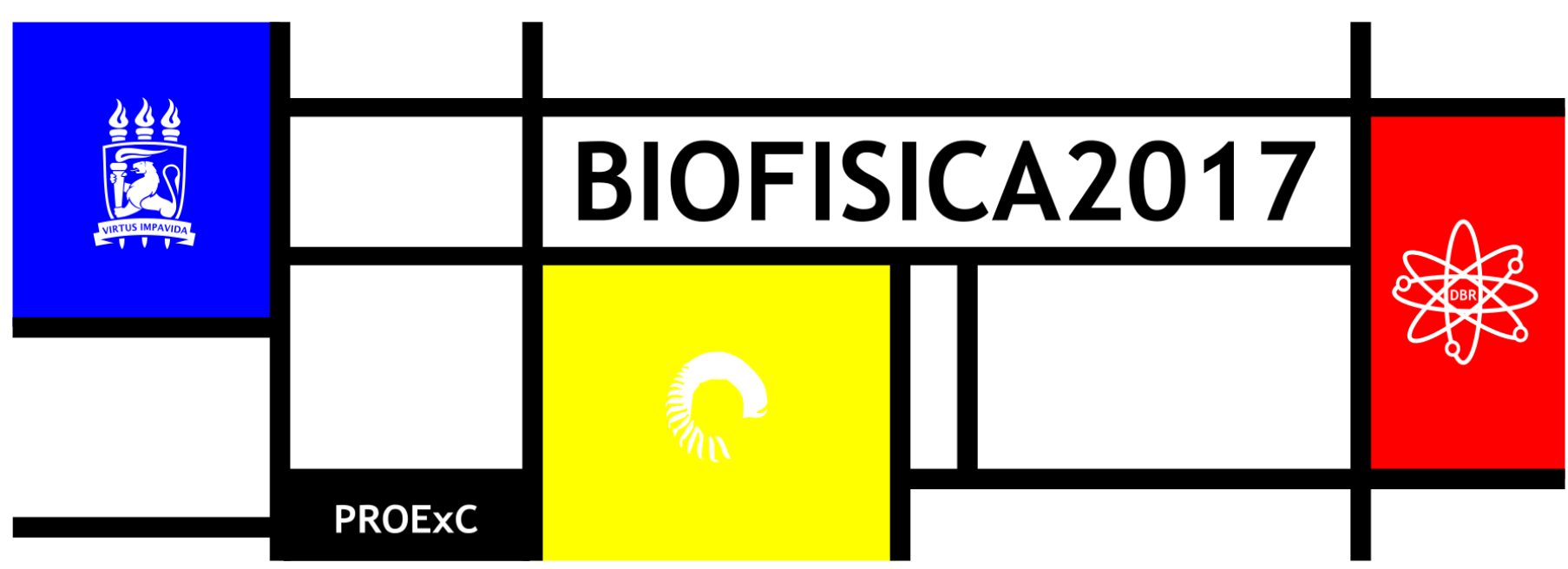

\title{
CULTIVO IN SITU DE RIZOPHORA MANGLE PARA SIMULAÇÃO DE CONTAMINAÇÃO AMBIENTAL POR RADIONUCLÍDEOS
}

\author{
José Daniel S. Paiva ${ }^{1 *}$, Marcelo Lira ${ }^{1}$, Elvis J. França ${ }^{1}$ \\ ${ }^{1}$ CRCN-NE \\ paivajds@gmail.com
}

\begin{abstract}
INTRODUÇÃO
A poluição ambiental decorrente da indústria nuclear é fato preocupante, principalmente pela liberação de isótopos radioativos que podem afetar os produtores primários e secundários, atingindo ecossistemas, comunidades, além da espécie humana (AKOB, 2007). Estuários, manguezais e floresta de restinga, típicos da Zona Costeira Brasileira, são ecossistemas complexos, cuja vegetação pode ser considerada uma das primeiras entradas de elementos químicos, incluindo radioativos, nos compartimentos desses ecossistemas (FRANÇA, 2015).

Alternativas para remediação de solos contaminados têm sido desenvolvida nos últimos anos, porém a maioria das pesquisas se concentra na utilização de organismos animais (COUTINHO et al., 2015).

A partir da constatação de Paiva (2014) sobre a acumulação de radionuclídeos naturais em espécies vegetais nativas de manguezais, este trabalho tem por objetivo demonstrar a possibilidade da criação de micro manguezais em casa de vegetação da espécie vegetal Rizophora mangle com o propósito futuro de simular contaminação do solo por radionuclídeos artificiais e possível utilização do vegetal como fitorremediador de contaminação ambiental por radionuclídeos.
\end{abstract}

\section{ESTUDO DE CASO I - PLÂNTULAS}

Para a verificação da adaptabilidade da $R$. mangle em casa de vegetação, incialmente foram realizados 24 transplantes de indivíduos vegetais e de $15 \mathrm{~cm}$ de seus respectivos (Figura 1).

0 procedimento foi realizado no manguezal às margens do Rio Arinquindá, localizado nas coordenadas de latitude $8^{\circ} 40^{\prime} 05^{\prime \prime}$ 'S e longitude $35^{\circ} 06^{\prime} 40^{\prime}$ ' $\mathrm{W}$, entre o município de Tamandaré e Rio Formoso, litoral sul de Pernambuco. Este local foi selecionado devido ao grau de conservação do manguezal (PAIVA, 2014).

A retirada das plântulas foi realizada com cuidado, tentando-se evitar ao máximo o manuseio brusco, bem como qualquer ação que viesse a comprometer as raízes, caule e folhas. As plântulas selecionadas tinham altura média variando entre 30 e $50 \mathrm{~cm}$, com mínimo de 4 folhas, respeitando-se a proporção adequada entre a parte aérea e o recipiente.

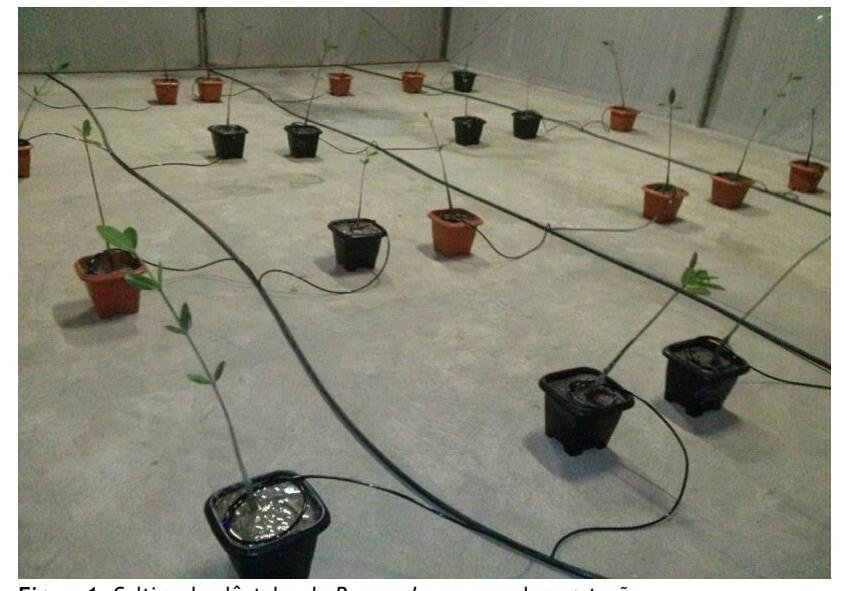

Figura 1. Cultivo de plântulas de R. mangle em casa de vegetação

Foi utilizada uma casa de vegetação com um rígido controle de irrigação, no qual os indivíduos foram cultivados durante três meses. Conforme Figura 1, a reposição dos nutrientes essenciais às espécies foi realizada a partir das irrigações diárias (gotejamento) de $2 \mathrm{~min} /$ dia e vazão $125 \mathrm{ml} / \mathrm{min}$ com água do próprio Estuário.

0 procedimento adotado no estudo de caso I não obteve êxito. Após o início do cultivo in situ não foi verificado crescimento das plântulas, gradativamente as folhas foram fenecendo até secar e morrerem totalmente no terceiro mês de cultivo. Os fatores causadores do insucesso ainda são desconhecidos, porém suspeitase que o transporte, a qualidade das mudas, a baixa umidade da estufa (inferior a $40 \%$ ) e o excessivo acréscimo de sal proveniente da água da irrigação tenham sido a causa da mortandade das plântulas.

\section{ESTUDO DE CASO II - PROPÁGULOS}

Após a confirmação da senescência das plântulas do Estudo de Caso I, procedeu-se uma nova coleta nas mesmas coordenadas geográficas, no entanto coletaram-se 20 propágulos de altura média de $25 \mathrm{~cm}$ em detrimento as plântulas desenvolvidas conforme o trabalho de DE ARAÚJO et al. (2014). 
Perfis de $30 \mathrm{~cm}$ de substrato foram amostrados e acondicionados em recipiente do tipo caixa d'água de 250 L com sistema de drenagem, que permite a recirculação da água utilizada. Posteriormente, realizou-se a estaquia dos propágulos no substrato. Para estimular a emissão de raízes e crescimento das plântulas, realizou-se a adubação foliar nos propágulos com macro e micronutrientes.

O sistema de drenagem montado (Figura 2) consiste em uma camada de $2 \mathrm{~cm}$ de brita coberta com feltro e uma torneira instalada na parte inferior para realização da recirculação, ou seja, simulação das marés.

Um sistema de irrigação por aspersão também foi montado, com o proposito de manter a umidade da estufa em níveis semelhantes ao encontrado no habitat natural. Para o controle de temperatura e umidade, são necessárias oito irrigações diárias com água potável por 10 minutos cada.
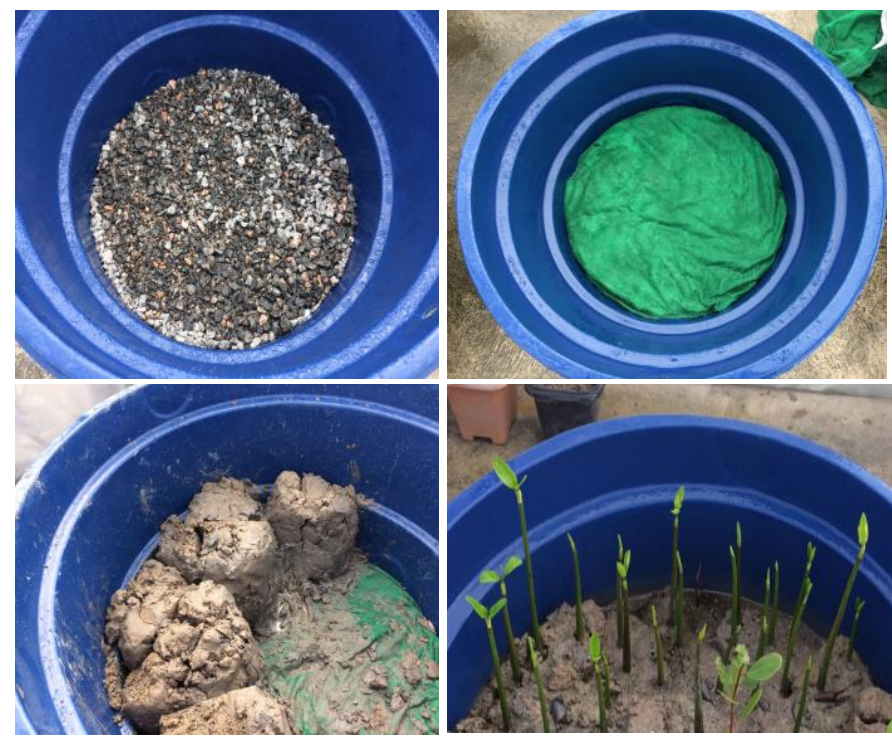

Figura 2. Cultivo de R. mangle de acordo com o Estudo de Caso II. Da esquerda para direita: Brita; Feltro; Substrato de manguezal; Plântulas em desenvolvimento.

Com o estudo de caso II, proporcionou-se a consolidação do substrato com um aumento substancial no recipiente de cultivo e controlou-se a umidade, não deixando cair a níveis inferiores a $60 \%$.

Os resultados foram surpreendentes, uma vez que os propágulos começaram a se desenvolver com apenas um mês de cultivo, houve desenvolvimento e aumento do número de folhas por individuo. Nenhuma senescência foi verificada, sendo que a taxa de estabelecimento foi aproximadamente $90 \%$.

\section{CONSIDERAÇÕES FINAIS}

Apesar da natureza halófita e da adaptabilidade a ambientes quentes, as plântulas de $R$. mangle não suportaram os transplantes, prejudicados também pelo tipo de irrigação e a ausência de controle de temperatura e umidade da casa de vegetação.

A irrigação por gotejamento com a água do estuário, sem sistema de drenagem e de recirculação da água acrescentava diariamente doses de sais, pois a água acaba por evaporar e os sais se depositavam no substrato do experimento I.

A partir do controle dos fatores acima descritos, os propágulos desenvolveram-se rapidamente, obtendo-se sucesso no cultivo in situ de $R$. mangle.

\section{REFERÊNCIAS}

AKOB, D.M.; MILLS, H.J.; KOSTKA, J.E. Metabolically active microbial communities in uranium contaminated subsurface sediments. FEMS Microbiology Ecology, v. 59, p. 95-107, 2007.
DE ARAÚJO, E. C.; DA COSTA, R. S.; LOPES, E. C.; DAHER, R. F.; FERNANDES, M. E. B. Qualidade das mudas de espécies arbóreas de mangue cultivadas em viveiro e diferentes substrates. Acta Ambiental Catarinense, v. 11, p. 22-32, 2014.

COUTINHO, P. W. R.; CADORIN, D. A; NORETO L. M.; GONÇALVES JÚNIOR, A. C. Alternativas de remediação e descontaminação de solos: biorremediação e fitorremediação. Nucleus, v. 12 , p. 59-68, 2015.

FRANÇA, E. J.; FERREIRA, S. F.; NETO SILVA, P. C.; FARIAS, E. G.; FIGUEIRA, R. L. C.; RIBEIRO, A. P. Natural radiouclides in the Brazilian Coast region: 1. Estuarine Complex Cananéia-Iguapé, São Paulo. In: International Conference Atlantic Conference, São Paulo, 2015, 6p.

PAIVA J. D. S. Plantas nativas na Costa Pernambucana: Bioacumuladores de radionuclídeos naturais e artificiais. Dissertação (Mestrado). Recife, Universidade Federal de Pernambuco, 2014. 82p. 